\title{
Avaliação de extratos vegetais no controle de mosca-branca, Bemisia tabaci biótipo B em abóbora ${ }^{1}$
}

\author{
Evaluation of plant extracts in the control of whitefly Bemisia tabaci biotype B in \\ squash
}

\author{
Bruno Marcus Freire Vieira Lima ${ }^{2 *}$, José Osmã Teles Moreira ${ }^{3}$ e Carlos Alberto Aragão ${ }^{3}$
}

\begin{abstract}
RESUMO - A abóbora (Cucurbita moschata Duch.) é uma cultura de importância para a agricultura familiar da região Nordeste do Brasil. No entanto, a ocorrência do prateamento das folhas da aboboreira ocasionado pela mosca-branca, Bemisia tabaci biótipo B limita sua produção, causando prejuízos aos agricultores. O objetivo deste trabalho foi avaliar a eficiência de extratos vegetais sobre o nível populacional de ninfas de mosca-branca em abóbora cv. Jacarezinho. O experimento foi instalado em campo experimental, em blocos casualizados, constituído de seis tratamentos e três repetições. As aplicações dos extratos vegetais foram feitas com intervalo de sete dias, fazendo-se uso de substâncias extraídas das seguintes plantas: canudo (Ipomoea carnea subsp. fistulosa), mamona (Ricinus communis L.), tinguí (Mascagnia rigida Griseb), cardo-santo (Argemone mexicana L.), e o óleo comercial Natuneem ${ }^{\circledR}$. Todos os extratos vegetais obtiveram eficiência no controle de ninfas $B$. tabaci, sendo o R. communis $(75,49 \%)$, M. rigida $(73,99 \%)$, I. carnea $(72,24 \%)$, óleo de nim $(70,4 \%)$ e A. mexicana $(69,16 \%)$.
\end{abstract}

Palavras-chave: Abóbora. Inseticidas vegetais. Pragas agrícolas-controle.

\begin{abstract}
The squash (Cucurbita moschata Duch.) is an important crop for family farmers in the northeast of Brazil. However, the occurrence of leaf silvering caused by the whitefly, Bemisia tabaci biotype B, limits production, causing losses to farmers. The aim of this study was to evaluate the efficiency of plant extracts on the population levels of whitefly nymphs on the squash cv. Jacarezinho. The experiment was conducted at an experimental field, in a randomized block design consisting of six treatments and three replications. Applications of plant extracts were made at an interval of seven days, making use of substances extracted from the following plants: Ipomoea carnea subsp. Fistulosa, castor bean (Ricinus communis L.), Tingui (Mascagnia rigida Griseb), cardo-santo (Argemone mexicana L.), and the commercial oil product Natuneem ${ }^{\circledR}$. All of the plant extracts were efficient in the control of the B. Tabaci nymphs, with R. communis (75.49\%), M. rigida $(73.99 \%)$, I. carnea $(72.24 \%)$, neem oil (70.4\%) and A. mexicana $(69.16 \%)$.
\end{abstract}

Key words: Pumpkin. Vegetables insecticides. Agricultural pest-control.

\footnotetext{
*Autor para correspondênica

${ }^{1}$ Recebido para publicação em 11/08/2011; aprovado 27/02/2013

Parte da Dissertação de Mestrado do curso de Pós-Graduação em Horticultura Irrigada do primeiro autor defendida na UNEB

${ }^{2}$ Departamento de Tecnologia e Ciências Sociais/UNEB, Campus III, av. Edgard Chastinet, s/n, São Geraldo, Juazeiro-BA, Brasil, 48.905-680, brunomfvl@gmail.com

${ }^{3}$ Departamento de Tecnologia e Ciencias Sociais/UNEB, Campus III, av. Edgard Chastinet, s/n, Sao Geraldo, Juazeiro-BA, Brasil, 48.905-680, jomoreira@uneb.br, carlosaragao@hotmail.com
} 


\section{INTRODUÇÃO}

A abóbora (Cucurbita moschata Duch.) tem como centro de origem a região central do México (FILGUEIRA, 2008). É uma hortaliça largamente cultivada no Brasil, especialmente na região Nordeste, onde as condições de clima são muito favoráveis ao seu cultivo, constituindo-se em alimento básico de populações de baixa renda (CASTRO; MAGALHÃES, 2006). O cultivo de abóbora jacarezinho é de ciclo curto, o que garante o retorno do capital investido em pouco tempo; além de apresentar algumas vantagens em relação às outras hortaliças, como por exemplo, facilidade na colheita e póscolheita, pois na maioria das vezes colhe-se o fruto maduro (2 a $3 \mathrm{~kg}$ em média, cor da casca vede escuro, mesclado com pontuações, estrias creme e polpa avermelhada) e não se necessita de embalagem já que transporte é feito a granel, comercializados sem passar por classificação em caminhões (CASTRO; MAGALHÃES, 2006). No Ceará, a cultivar Jacarezinho, com irrigação localizada, plantio em espaçamento 2,0 x 0,3 m, com cerca de 16.600 plantas por hectare possui produção em torno de 30 toneladas (CASTRO; MAGALHÃES, 2006). A mosca-branca, Bemisia tabaci Gennadius biótipo B, prejudica a aboboreira, por meio de sua alimentação, induzindo o prateamento das folhas (SCHMALSTIG; MCAUSLANE, 2001). Summers e Stapleton (2002), além de confirmarem a ocorrência de moscabranca nas espécies $C$. pepo, $C$. moschata e $C$. maxima, ainda a apontam como uma das principais pragas da cultura.

A utilização de inseticidas sintéticos tem sido o principal método de controle da praga. Porém, o uso indiscriminado e geralmente de forma incorreta desses princípios ativos tem aumentado o número de aplicações e diminuído suas eficiências, principalmente devido ao desenvolvimento de populações de insetos resistentes. Tal uso agrava o problema de contaminação dos produtos agrícolas, de agricultores e do ambiente (BORGONI; VENDRAMIM, 2003). Extratos de plantas estão sendo pesquisados, e em grande parte já com efeito comprovado, para o controle de pragas (GONÇALVES; BLEICHER, 2006). A atividade inseticida de extratos de plantas pode ser manifestada através da mortalidade direta, repelência, esterilidade, interferência no desenvolvimento e modificação no comportamento dos artrópodes (SILVA et al., 2010). Portanto, objetivou-se com esse trabalho foi avaliar a eficiência dos de extratos vegetais como alternativa ao uso de inseticidas sintéticos no controle de ninfas de mosca-branca em plantas de abóbora Jacarezinho.

\section{MATERIAL E MÉTODOS}

O estudo foi conduzido no Campo Experimental de Horticultura irrigada no Departamento de Tecnologia e Ciências Sociais - DTCS/ Campus III - UNEB, no município de Juazeiro - BA, tendo início em 08 de junho de 2008 e término em 26 de outubro de 2008. O solo utilizado foi do tipo Neossolo Flúvico, segundo a classificação de solos (BAHIA, 1989), sendo avaliado quanto à fertilidade através de análise de solo. De acordo com dados georeferenciais do experimento, constam coordenadas geográficas de $09^{\circ} 25^{\prime} 10,59^{\prime}$ ' para latitude sul e $40^{\circ} 29^{\prime} 15,16^{\prime \prime}$ para longitude oeste, com altitude aproximada de 366 metros. O clima regional é do tipo Bswh, semiárido, de acordo com a classificação de Köppen, precipitação média anual em torno de $619,4 \mathrm{~mm}$, sendo a temperatura média anual de $25,9^{\circ} \mathrm{C}$, a mínima de $20,7^{\circ} \mathrm{C}$ e a máxima de $31,9^{\circ} \mathrm{C}$, com a temperatura do mês mais frio de $15,3^{\circ} \mathrm{C}$ em junho, e do mês mais quente $37,3^{\circ} \mathrm{C}$, em novembro.

O experimento foi constituído de seis tratamentos e três repetições, dos quais quatro tratamentos constaram do uso de extratos vegetais e um tratamento com óleo emulsificado, além do tratamento testemunha onde utilizou-se água. $\mathrm{O}$ delineamento utilizado foi em blocos casualizados, sendo cada parcela constituída de três fileiras com 10 plantas cada, resultando em um total de 30 plantas por parcela, adotando-se espaçamento de $0,30 \mathrm{~cm} \times 2,00 \mathrm{~m}$ para plantas de aboboreira. Os tratamentos constituíram-se dos seguintes extratos: óleo essencial de nim na dose de $100 \mathrm{~mL}$ para 20 litros de água; o tratamento com o Canudo (Ipomoea carnea subsp. fistulosa), utilizando folhas e frutos na proporção de $1 / 2$ como partes da planta, sendo secas a sombra e Triturado, $30 \mathrm{~g}$ do material seco diluído em $100 \mathrm{~mL}$ de água, homogeinizado em liquidificador, adicionando-se 1,0 litro de álcool etílico absoluto PA, após 24 horas de repouso, diluído a 5\% em água, para cada mL da solução (MOHAPATRA; PONNUNASAN; NANAYANASAMY, 2010; SUJATHA; JOSEPH; SUMI, 2010); a Mamona (Ricinus communis L.), utilizado folhas e frutos (proporção de $1 / 2$ ) secos à sombra, triturados, utilizando solvente álcool etílico absoluto PA adicionando-se $200 \mathrm{ml}$ para 100 gramas do material triturado, filtrado após 24 horas e diluído a $10 \%$ em água destilada (RODRIGUEZ, 2000; SANTIAGO et al., 2008); o Cardo - santo (Argemone mexicana L.) foi utilizado folhas e flores (proporção de $1 / 2$ ) secos à sombra, 30 gramas adicionando-se a $300 \mathrm{~mL}$ de água quente a $100{ }^{\circ} \mathrm{C}$ por $60 \mathrm{~min}$ (ALI; RIZVI; KHAN, 2010; KULKARNI et al., 2009), sendo o material vegetal de canudo, mamona e cardo-santo colhidos no Campus III da UNEB, Juazeiro-BA; o Tinguí (Mascagnia rigida Griseb) foram utilizados folhas, secas à sombra e infusão de 50 gramas em 1.000 mL de água (RODRIGUES et al., 2008), o material foi colhido no Município de Curaçá-BA. Na testemunha foi utilizada água. 
A cultivar utilizada foi Jacarezinho, empregando 600 plântulas para a implantação do experimento. As plantas utilizadas para obtenção dos extratos foram colhidas com antecedência de acordo com o grau de secagem à sombra, para o preparo dos mesmos. Cada espécie de planta separadamente foi triturada em moinho de lâminas até se obter pó fino e de fácil diluição e preparação. As pulverizações foram efetuadas com pulverizador costal manual com capacidade para 20 L da solução e equipado com bico cônico D2 com aplicações no horário entre 16 e $18 \mathrm{~h}$. As aplicações foram feitas com intervalo de 7 dias, resultando em um total de 3 aplicações dos extratos vegetais. Para se evitar deriva do material aplicado foi utilizado o plástico de cobertura "mulching" com tutores de aço na altura de 1,20 $\mathrm{m}$ nas extremidades do bloco. Para avaliação, as folhas de aboboreira eram coletadas e acondicionadas em saco plástico transparente com dimensões de $20 \times 10 \mathrm{~cm}$. As folhas eram coletadas com um auxílio de uma tesoura de raleio e conservadas em refrigerador a uma temperatura variando de 8 a 10 ${ }^{\circ} \mathrm{C}$. As avaliações e aplicações com extratos vegetais iniciaram após a observação da incidência do inseto adulto na área experimental. O número de folhas coletadas para avaliações foi de 2 folhas por planta ou 16 folhas por parcela. As folhas foram avaliadas no laboratório de entomologia, sob microscópio estereoscópio registrando-se o número de ninfas. A partir da constatação da ocorrência da mosca-branca foi feita a primeira avaliação. Semanalmente, realizaramse avaliações foliares, três dias após cada pulverização. Foram feitas quatro avaliações. As folhas avaliadas foram coletadas na região mediana da planta $\left(4^{\mathrm{a}}\right.$ folha). Foi efetuada a análise de variância utilizando o programa Winstat bem como o teste de comparação de médias de Tukey a 5\%. Para obter a porcentagem de eficiência dos tratamentos, foi utilizada a fórmula de Abbott (1925).

\section{RESULTADOS E DISCUSSÃO}

O sintoma do prateamento da supefície da folha e a descoloração de frutos causados pela $B$. tabaci foram observados em campo. Os tratamentos com $A$. mexicana, I. carnea, $R$. communis e $M$. rigida diferiram significativamente da testemunha na primeira avaliação (Tabela 1).

Na primeira avaliação, constatou-se que o extrato de I. carnea obteve diferença significativa em controlar o nível populacional de ninfas alcançando uma média de 11,25 ninfas de mosca-branca/folha, enquanto a testemunha com uma média de 28,58 ninfas. O tratamento com o óleo de nim não diferenciou significativamente da testemunha após a primeira aplicação, demonstrando ação lenta, como inseticida, sobre as ninfas a princípio. A média de ninfas constatada no tratamento com óleo de nim foi de 18,12 , enquanto a da testemunha foi de 28,58 ninfas.

O extrato de $M$. rigida apresentou uma média de ninfas de 13,91 na primeira avaliação, ou seja, aproximadamente a metade da média da testemunha. O Tratamento com A. mexicana obteve o controle de ninfas após a primeira aplicação, com uma média de 14,04 ninfas.

Após a segunda aplicação dos extratos vegetais, ocorreu diferença significativa entre todos os tratamentos em relação à testemunha, sendo que o tratamento de M. rigida, obteve média de 5,12 ninfas em relação à testemunha, na qual foram registradas 26,95 ninfas. O extrato de $R$. communis alcançou um controle da média de ninfas também elevado, apresentando apenas 5,5 ninfas em média. Oóleo de nim, após a segunda aplicação, apresentou resultados mais marcantes do que na primeira aplicação, baixando a população de 18,12 em média de ninfas para uma média de 5,91 ninfas, expressando diferença significativa após duas aplicações em comparação à testemunha. Ocorreu diferença significativa do extrato

Tabela 1 - Número médio de ninfas de Bemisia tabaci, biótipo B, em folhas de abóbora submetida a tratamentos com extratos vegetais (Juazeiro-BA, 2008)

\begin{tabular}{lccc}
\hline \multicolumn{1}{c}{ Tratamentos } & Média após 1 ${ }^{\mathrm{a}}$ aplicação & Média após 2 a aplicação & Média após $3^{\mathrm{a}}$ aplicação \\
\hline Testemunha Natuneem $^{R}$ & $28,58 \pm 4,39 \mathrm{a}^{*}$ & $26.95 \pm 4.52 \mathrm{a}$ & $38.45 \pm 11.58 \mathrm{a}$ \\
A. mexicana & $18.12 \pm 5.83 \mathrm{a}$ & $5.91 \pm 2.48 \mathrm{~b}$ & $1.37 \pm 0.57 \mathrm{~b}$ \\
M. rigida & $14.04 \pm 6.50 \mathrm{~b}$ & $10.41 \pm 4.85 \mathrm{~b}$ & $2.12 \pm 0.78 \mathrm{~b}$ \\
R. communis carnea & $13.91 \pm 2.62 \mathrm{~b}$ & $5.12 \pm 2.41 \mathrm{~b}$ & $3.95 \pm 2.24 \mathrm{~b}$ \\
I. & $11.58 \pm 2.56 \mathrm{~b}$ & $5.50 \pm 3.03 \mathrm{~b}$ & $4.08 \pm 2.44 \mathrm{~b}$ \\
C.V $(\%)$ & $11.25 \pm 5.93 \mathrm{~b}$ & $7.62 \pm 3.26 \mathrm{~b}$ & $5.37 \pm 1.44 \mathrm{~b}$ \\
\hline
\end{tabular}

*As médias ( \pm EP) seguidas de letras iguais não diferiram significativamente pelo teste de Tukey a 5\%. Dados originais: para análise estatística foram transformados em $\sqrt{ }(x+0,5)$ 
de A. mexicana após a segunda aplicação, alcançando uma média do nível populacional de 10,41 ninfas. O tratamento com I. carnea foi satisfatório, baixando o nível populacional de 11,20 ( $1^{\text {a }}$ aplicação) para 7,62 ( $2^{\mathrm{a}}$ aplicação) em média de ninfas, após aplicação dos extratos vegetais.

Verificou-se, após a terceira aplicação dos tratamentos, que o óleo de nim apresentou alta eficiência de controle, demostrando que sua ação sobre o inseto é lenta a princípio, e progressiva após as aplicações subsequentes, alcançando média de 1,37 ninfas, enquanto que a testemunha registrava uma média de 38,45 ninfas. O extrato vegetal de $A$. mexicana promoveu controle de ninfas, depois da terceira aplicação, alcançando 2,12 ninfas, significativo ao ser comparado à testemunha nas três avaliações. Constatou-se ainda, em relação ao extrato de A. mexicana que, após a terceira aplicação, decresceu cerca de $1 / 4$ de média de ninfas em relação à segunda aplicação, que foi de 10,41. A $M$. rigida, com 3,95 em média, comportou-se como um extrato promissor no controle, diminuindo a média de ninfas de acordo com as aplicações mantendo diferença significativa em relação à testemunha após as três aplicações. Segundo Rodriguez et al. (2008), os componentes químicos presentes no extrato de $M$. rigida podem estar agindo sobre lagartas, inibindo sua alimentação e induzindo-as a procurar as folhas não tratadas para alimentação. Neste caso, pode-se sugerir, que em ninfas de B. tabaci, o princípio de mortalidade deve estar ocorrendo a partir da inibição da alimentação da seiva das folhas de aboboreira por estas ninfas. $\mathrm{O}$ extrato de $R$. communis obteve em média 4,08 ninfas por folha após a última aplicação. Já o extrato de $I$. carnea, na última aplicação, promoveu redução significativa do número de ninfas. De acordo com a fórmula de Abbott (1925), foi calculada a eficiência dos extratos vegetais como demonstrado na Figura 1.

O óleo de nim alcançou 70,4\% de eficiência média no controle de ninfas em condições de campo. Segundo Azevedo (2005) o extrato de nim é eficiente para controlar adultos e ninfas de mosca-branca em meloeiro. Martinez (2003) cita que a planta possui mais de 50 compostos terpenóides, a maioria com ação sobre os insetos. Por esse motivo, a probabilidade de um inseto desenvolver resistência é bastante reduzida, uma vez que inúmeros mecanismos são afetados ao mesmo tempo (CIOCIOLA JÚNIOR, 2002; GARCIA, 2000). Os componentes ativos mais relevantes são a salanina, 14-epoxiazadiradiona, meliantrol, melianona, vilosinina, meliacarpina e azadiractina. Há registro de ação sobre mais de 300 espécies, sendo a maior parte das investigações feita em laboratório (MARTINEZ, 2006). A azadiractina inibe a alimentação dos insetos, afeta o desenvolvimento das larvas, atrasa seu crescimento, reduz a fertilidade e fecundidade dos adultos, altera o comportamento, causando diversas anomalias nas células e na fisiologia dos insetos, resultando na morte principalmente das formas jovens (CIOCIOLA JÚNIOR, 2002). Já salanina, melantriol e nimbina apresentam efeito anti-alimentar (GARCIA, 2000). Silva, Bleicher e Araújo (2003) constataram que a eficiência dos tratamentos à base de azadiractina apresenta ação sistêmica prolongada. $\mathrm{O}$ extrato de $I$. carnea alcançou uma porcentagem média de eficiência

Figura 1 - Eficiência de controle dos tratamentos após aplicação dos extratos vegetais em abóbora cv. Jacarezinho

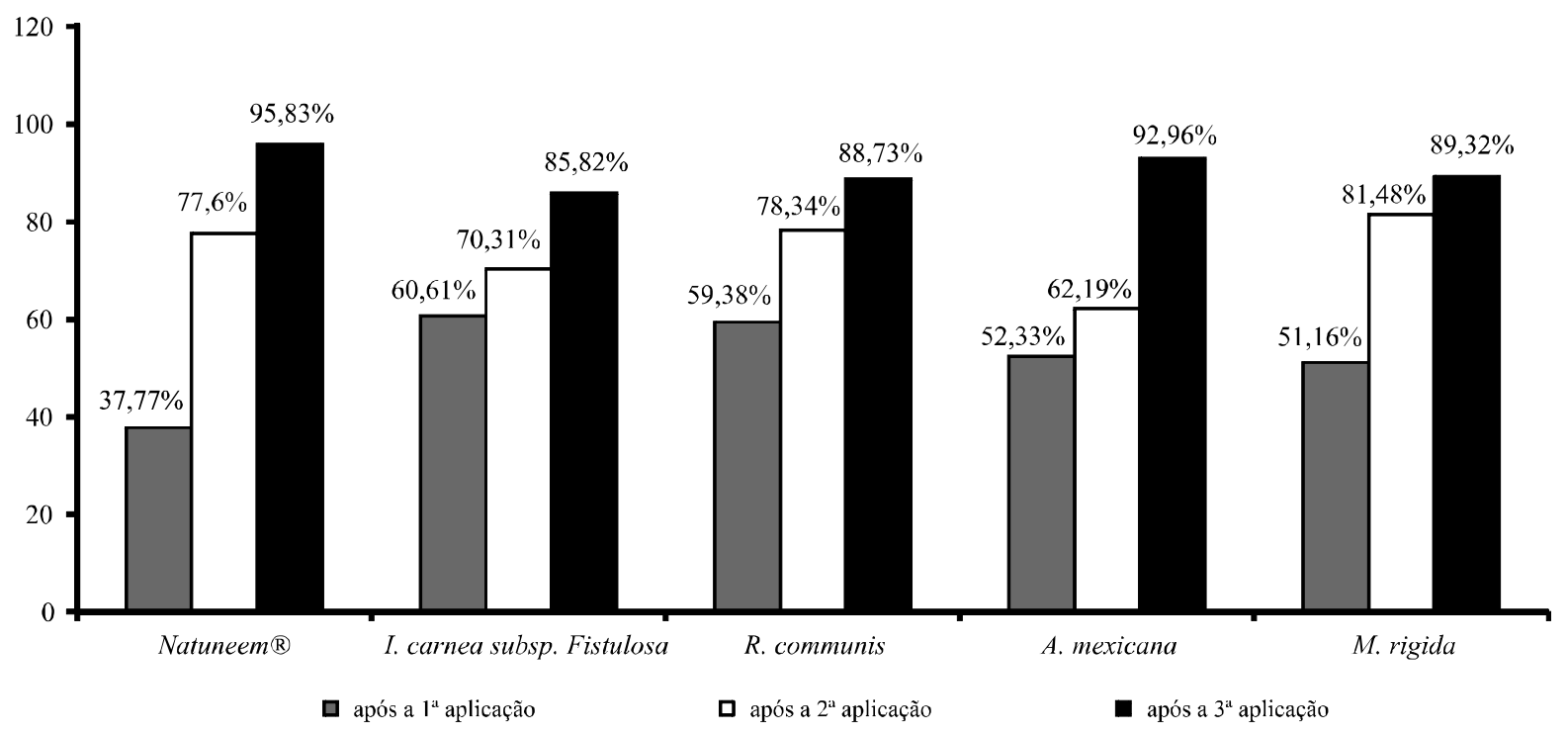


de $72,24 \%$. O principio ativo de I. carnea é o alcalóide indolizidínico swainsonina, tendo sido identificadas, também, calisteginas B1, B2, B3 e C1 (HARAGUCHI et al., 2003), sendo alcalóides distribuídos nas espécies das famílias Solanaceae e Convolvulaceae (WATSON et al., 2001). A I. carnea vem sendo estudada e seus componentes identificados qualitativamente e quantitativamente por atuarem inibindo a função de enzimas participantes do complexo metabolismo dos carboidratos (SCHWARZ et al., 2004). Haraguchi et al. (2003) detectaram também o aminoácido N-metiltrans4-hidroxi-L-prolina como constituintes. O Extrato de $R$. communis foi eficiente no controle de ninfas de $B$. tabaci, alcançando média das três aplicações de 75,49\%. A aplicação do extrato aquoso de $R$. communis em feijão diminuiu a população e provocou necrotização em ninfas de B. tabaci (RODRIGUEZ, 2000). Todas as partes da mamona são tóxicas, particularmente as sementes, pela presença de ricina e a ricinina. A ricina está formada por duas proteínas, uma delas é tóxica e a outra associada com a albumina. Com relação à ricinina, é um alcalóide presente na semente e na folha, solúvel em água e álcool, éter e clorofórmio. É um Ester metílico do ácido ricínico que possui um grupo nitrilo e uma função cetônica, que não forma sais com ácido (RODRIGUEZ, 2000). O extrato de A. mexicana alcançou 69, 16\% de eficiência média de controle após 03 aplicações. Bioensaio do extrato de A. mexicana revelou três fenólicos inibidores de germinação e cromatografia em papel revelou a presença de p-hidroxibenzóico, ácidos vanílico e salicílico (BURHAN; SHAUKAT, 1999). Quanto aos componentes tóxicos, foram encontrados os alcalóides berberina, protopina, sarguinarina, optisina e chelerytherina (SHARMA; SHARMA; KOHLI, 2010). $\mathrm{O}$ extrato de $M$. rigida obteve média de eficiência de $73,98 \%$. Substâncias denominadas cromonas como princípio ativo da $M$. rigida, é provável que a planta contenha fluoracetato (RIET-CORREA; MEDEIROS; DANTAS, 2006). O extrato de $M$. pubiflora provocou a maior mortalidade pupal em Spodoptera frugiperda (J E Smith) (RODRIGUES et al., 2008).

Nas condições do Vale do São Francisco, todos os extratos vegetais utilizados no controle de moscabranca na cultura da abóbora cv. Jacarezinho obtiveram eficiência e significância em comparação a testemunha. O extrato vegetal de $R$. communis, obteve média de eficiência das três aplicações de 75,49\%. O extrato de M. rigida alcançou média de eficiência de $73,98 \%$. O extrato de canudo $I$. carnea, com porcentagem média de eficiência de $72,24 \%$, o óleo de nim alcançou $70,4 \%$ de eficiência no controle de ninfas de $B$. tabaci e o extrato de A. mexicana atingiu $69,16 \%$ de eficiência média de controle após três aplicações.

\section{REFERÊNCIAS}

ABBOTT, N S. A method of computing the effectiveness of on inseticide. Journal of economic Entomology, v. 18, n. 1 p. $265-267,1925$.

ALI, A.; RIZVI P. Q.; KHAN, F. R. Bio-efficacy of some plant leaf extracts against mustard aphid, lipaphis erysimi kalt. on indian mustard, Brassica juncea. Journal of plant protection research, v. 50, n. 2, p. $130-132,2010$.

AZEVEDO F. de R. et al. Eficiência de produtos naturais para o controle de Bemisia tabaci biótipo B (Hemiptera: Aleyrodidae) em meloeiro. Arquivo Instituto Biológico, v. 72, n. 1, p. 73 79, 2005.

BAHIA. Comissão Estadual de Fertilidade do Solo. Manual de adubação e calagem para o estado da Bahia. 2. ed. Salvador: Embrapa, Ceplac, Seagri, Nitrofertil, 1989. 173 p.

BOGORNI P. C.; VENDRAMIN J. D. Bioatividade de Extratos Aquosos de Trichilia spp. sobre Spodoptera frugiperda (J. E. Smith) (Lepidoptera: Noctuidae) em Milho. Neotropical Entomology, v. 32, n. 4, p. 665-669, 2003.

BURHAN, N; SHAUKAT, S. S. Allelopathic potential of Argemone mexicana L. a tropical weed, Pakistan Journal of Biological Sciences, v. 2, n. 4, p. 1268-1273, 1999.

CASTRO, E B; MAGAlHÃES, J. S. B. Produção e mercado da Abóbora no Ceará. Fortaleza: SEAGRI, 2006. 18 p.

CIOCIOLA JÚNIOR, A. I.; MARTINEZ, S. S. Nim: alternativa no controle de pragas e doenças. Belo Horizonte: EPAMIG, 2002. 24 p. (Boletim Técnico, 67).

FILGUEIRA, F. A. R. Novo Manual de Horticultura. 3. ed. Minas Gerais: Visçosa, 2008. 421 p.

GARCIA, J. L. M. O nim indiano: o bioprotetor natural. 2000. Disponível em: <http://www.agrisustentavel.com/doc/ nim.htm>. Acesso em: 26 nov. 2004.

GONÇALVES, M.E. de; BLEICHER,E. Uso de extratos aquosos de nim e azadiractina via sistema radicular para o controle de mosca-branca em meloeiro. Revista Ciência Agronômica, v. 37 , n. 2, p. 182-187, 2006.

HARAGUCHI M. et al. Alkaloidal components in the poisonous plant Ipomoea carnea (Convolvulaceae). Journal of Agricultural Food Chemistry, v. 51, n. 17, p. 4995-5000, 2003.

KULKARNI, J.; KAPSE, N.; KULNARNI D.K. Plant-based pesticide for control of Helicoverpa armigera on Cucumis Sativus. Asian Agri-History, v. 13, n. 4, p. 327-332, 2009.

MARTINEZ, S. S. O nim (Azadirachta indica) um inseticida natural. Disponível em: <http:/www.iapar.gov.pr.br>. Acesso em: 12 maio 2006

MARTINEZ, S. S. O Uso do Nim no Café e em outras Culturas, Revista Agroecologia Hoje, v. 4, n. 21, p. 13-14, 2003.

MOHAPATRA, p.; ponNurasan, n.; narayanasamy, p. Tribal pest control practices of tamil nadu for sustainable 
agriculture. Indian Journal of Traditional Knowledge, v. 8, n. 2, p. 208-224, 2009.

RIET-CORREA, F.; MEDEIROS, R. M. T.; DANTAS, M. F. A. Plantas tóxicas da Paraíba. Campina Grande-PB: UFCG, 2006. 9 p.

RODRIGUES, S. R. et al. Atividade inseticida de extratos etanólicos de plantas sobre Spodoptera frugiperda (J.E.Smith) (Leptopdera: Noctuidae). Agrarian, v. 1, n. 1, p. 133-144, 2008.

RODRIGUEZ, C. H. La Higuerilla: uma alternativa contra las plagas. México: RAPAM, 2000. 13 p.

SANTIAGO, G. P. et al. Efeitos de extratos de plantas na biologia de Spodoptera frugiperda (J. E. SMITH, 1797) (Lepidoptera: Noctuidae) mantida em dieta artificial. Ciência e Agrotecnologia, v. 32, n. 3, p. 792-796, 2008.

SCHMALSTIG, J. C.; MCAUSLANE, H. J. Developmental anatomy of zucchini leaves with squash silverleaf disorder caused by the silverleaf whitefly. Journal of the American Society for Horticultural Science, v. 126, n. 5, p. 544-554, 2001.

SCHWARZ, A. et al. Identificação de princípios ativos presentes na Ipomoea carnea brasileira. Revista Brasileira de Ciências Farmacêuticas, v. 40, n. 2, p. 181-187, 2004.
SHARMA, S.; SHARMA, M. C.; KOHLI, D. V. Pharmacological screening effect of ethanolic and methanolic extract of fruits of medicinally leaves. Digest Journal of Nanomaterials and Biostructures, v. 5, n. 1, p. 229-232, 2010.

SILVA, L. D.; BLEICHER, E.; ARAÚJO, A. C. Eficiência de azadiractina no controle de mosca-branca em meloeiro sob condições de casa-de-vegetação e campo. Horticultura Brasileira, v. 21, n. 2, p. 198-201, 2003.

SILVA, M. B. da et al. Controle alternativo de pragas e doenças na agricultura organic. Viçosa:, EPAMIG, 2010. $232 \mathrm{p}$.

SUJATHA, S.; JOSEPH, B.; SUMI, P. S. Medicinal plants and its impact of ecology, nutritional effluents and incentive of digestive enzymes on Spodoptera litura (Fabricious). Asian Journal of Agricultural Research, v. 4, n. 4, p. 204-211, 2010.

SUMMERS C. G.; STAPLETON, J. J. Use of UV reflective mulch to delay the colonization and reduce the severity of Bemisia argentifolii (Homoptera: Aleyrodidae) infestations in cucurbits. Crop Protection, v. 21, n. 10, p. 921-928, 2002 .

WATSON, A. A. et al. Polyhydroxylated alkaloids - natural occurrence and therapeutic applications. Phytochemistry, v. 56, n. 1, p. 265-295, 2001. 